\title{
CURRENT EVIDENCE FOR THE ROLE OF ANTI-NEURONAL ANTIBODIES IN PARANEOPLASTIC NEURONAL DISORDER
}

\author{
${ }^{1}$ Department of Medicine, Usmanu Danfodiyo University Teaching Hospital Sokoto, Nigeria \\ ${ }^{2}$ Department of Medicine, University of Maiduguri Teaching Hospital, Nigeria
}

\begin{abstract}
Paraneoplastic Neurologic syndromes (PNS) are rare heterogeneous group of disorders associated with cancer, caused by mechanisms other than, direct infiltration, metastasis, infection, coagulopathy, metabolic and nutritional deficits or consequences of therapy. These syndromes can affect any area of the nervous system, including central nervous system, peripheral and autonomic nervous system, neuromuscular junction, and muscles.

Over the last five decades three waves of interest are noted in paraneoplastic neurological syndromes: First, the clinical and pathological recognition of PNS; and then the discovery of immunological mechanisms characterized by the presence of antibodies and associated cytotoxic $\mathrm{T}$ cell responses against intracellular antigens, and more recently, the surge of antibodies ('onconeural' antibodies) against synaptic and cellular surface proteins

Although paraneoplastic neurological syndromes are uncommon and not completely understood, their antibody associations are important because of the antibody's aetiological connection with the underlying neoplasm. The paraneoplastic autoantibody may provide a roadmap to early diagnosis of the underlying neoplasm, prompt treatment of which can sometimes improve the neurological outcome. The disorder often predate the diagnosis of the underlying neoplasm, providing a pathway for detecting cancer at an earlier and amenable stage. Evaluations for paraneoplastic antibodies are sometimes negative but do not rule out the diagnosis of a paraneoplastic disorder. Therefore, relevant clinical presentations should suggest a paraneoplastic syndrome, even in the absence of paraneoplastic antibodies and prompt search for occult neoplasm.
\end{abstract}

\section{INTRODUCTION}

$\mathrm{P}$ araneoplastic Neurologic syndromes (PNS) are rare heterogeneous group of disorders associated with cancer, caused by mechanisms other than, direct infiltration, metastasis, infection, coagulopathy, metabolic and nutritional deficits or consequences of therapy ${ }^{1}$. These syndromes can affect any area of the nervous system, including central nervous system, peripheral and autonomic nervous system, neuromuscular junction, and muscles. The pattern of involvement is usually multifocal (e.g. encephalomyelitis), though, it can be limited to a single area (e.g. cerebellar degeneration).

The incidence and prevalence of Paraneoplastic disorders varies with the neurologic syndrome and type of tumor. The most commonly reported syndromes $^{2}$ are Lambert-Eaton Myasthenic Syndrome (LEMS), which affects 2-3\% of all patients with small-cell lung cancer (SCLC) and Myasthenia Gravis, which affects approximately,
$15 \%$ of patients with thymoma. Others are: Progressive Cerebellar Degeneration (PCD) (2 per 1000 cancer cases), Subacute Sensory Neuronopathy (NSS) (3-7 per 1000 cancer cases), and Limbic Encephalitis (LE) (3 per 1000 cancer cases) $)^{3}$."Overall, it is estimated that less than $1 \%$ of patients with neoplasm have associated paraneoplastic syndrome ${ }^{2}$. Usually the neurologic syndrome predates the diagnosis of cancer in $50 \%$ to $80 \%$ of cases ${ }^{4}$.

Over the last five decades three waves of interest are noted in paraneoplastic neurological syndromes: First, the clinical and pathological recognition of PNS; and then the discovery of immunological mechanisms characterized by the presence of antibodies and associated cytotoxic $\mathrm{T}$ cells responses against intracellular antigens, and more recently, the surge of antibodies ('onconeural' antibodies) against synaptic and cellular surface proteins

'Onconeural' antibodies are important in the 
diagnosis and management of paraneoplastic disorders. These antibodies are specific for the type of neoplasm rather than for a particular paraneoplastic syndrome. ${ }^{5}$ Paraneoplastic antibodies may be detected in the serum and/or Cerebrospinal fluid (CSF), and in some cases, there is immunological evidence of intrathecal synthesis of these antibodies. Other associated CSF inflammatory changes include: lymphocytic pleocytosis, intrathecal synthesis of $\mathrm{IgG}$ and oligoclonal bands ${ }^{6}$.The mainstay of therapy is the early identification and elimination of the underlying tumor. ${ }^{7}$ Recent advances have improved understanding and ability to recognize PNDS. These include additional clinical descriptions of new paraneoplastic disorders, an increase in the number and variety of diagnostic antibody markers, and improvements in cancer imaging such as Fluorodeoxyglucose Positron Emission Tomography (FDG-PET). ${ }^{8}$ This review focuses on the current evidence for the role of antineuronal antibodies in the pathogenesis, diagnosis, and treatment of paraneoplastic neurological disorders.

\section{DEFINITION}

"Paraneoplastic neurological syndromes (PNS) are a heterogeneous group of neurologic disorders caused by an immune response to an underlying malignancy. Thus, the neurologic effects are not the result of metastases, nutritional abnormalities, amyloid deposition or adverse effects of cancer treatments".

\section{CLASSIFICATION}

Broadly Paraneoplastic neurological syndromes can be subdivided into 'classical' and 'non-classical' PNDS (table 1). Some PNDS are defined as 'classical' because their presence strongly suggests an underlying cancer. Other disorders are defined as 'nonclassical' because, "although they are sometimes associated with cancer, more often they $\operatorname{are~not"~}^{10}$ (table 1)

4. ROLE OF ANTINEURONAL ANTIBODIES IN THE PATHOGENESIS OF PARANEOPLASTIC NEUROLOGIC SYNDROME

4.1 MECHANISMS: The current hypothesis for the pathogenesis of paraneoplastic neurologic syndromes implies an immune reaction against antigens present in both the nervous system and the tumour ${ }^{11}$. Most paraneoplastic neurological disorders are thought to be caused by an autoimmune reaction directed against 'onconeural' antigens expressed by neurons and tumour cells ${ }^{11}$.This concept reflects the ability of neoplasms to provoke an immune response that results in multifaceted group of diseases that can affect the entire neuroaxis, neuromuscular junction, and muscles. The central theory of autoimmunity in paraneoplastic syndrome is that of 'molecular mimicry'; which postulates that tumour cells express 'onconeural' antigen(s) that are similar or antigenically related to molecules normally expressed by neurons ${ }^{6}$. Therefore, when the body tries to eliminate tumor cells, it launches an immune response, and this response 'spills over' to attack neurons expressing the same or related $\operatorname{antigen}(\mathrm{s}){ }^{5}$

Pathological studies in some PND cases (e.g. cerebella degeneration and limbic encephalitis) have demonstrated infiltration of the tumour and target nervous tissue by inflammatory cells. ${ }^{12}$ The inflammatory lesion consist of perivascular accumulations of CD4+ $\mathrm{T}$ cells and $\mathrm{B}$ cells, as well as parenchymal CD $8+T$ cells and microglia. ${ }^{13,14}$ Therefore, both $\mathrm{T}$ cells and antibody mediated processes have been implicated (figure 1). Studies have showed that activated T cells from the CSF of a patient with progressive cerebellar degeneration could lyse target cells presenting Yo antigen in vitro. $^{13,15}$ Additionally, cerebrospinal fluid (CSF) assay in patients with paraneoplastic syndrome reveals lymphocytic pleocytosis, elevated protein, increased IgG synthesis, and oligoclonal bands, supporting the immunological pathology. ${ }^{16}$ For example aEuropean study in 2010, revealed abnormal CSF in $93 \%$ of the cases; pleocytosis in $39 \%$, elevated protein in $67 \%$ and oligoclonal bands in $63 \% .^{17}$

Antineuronal antibodies can be detected in the serum and/or cerebrospinal fluid of many patients with paraneoplastic syndrome ${ }^{18}$ (Figure 1). Detection of one or more of the 'onconeural' antibodies in the 
blood or cerebrospinal fluid usually suggests the paraneoplastic nature of the neurological presentation, whether the tumour has been detected or not. ${ }^{18}$ Findings in some studies suggests that presence of antineuronal antibodies indicates immune mediated elimination of tumour cells in patients with paraneoplastic syndrome. ${ }^{19}$ Thus, it was postulated that patients with antibodyassociated paraneoplastic syndrome have better oncologic outcome when compared with PNS patients without demonstrable antibody. ${ }^{7,20}$ However, reports of large series reviews did not show any significant difference in oncologic outcome between antibody-associated paraneoplastic patients and patients who do not have antibodies. ${ }^{1}$

Although some antibodies such as: NMDA receptor antibodies in anti-NMDAR encephalitis, ${ }^{21}$ anti-presynaptic calcium channel antibodies associated with EatonLambert syndrome, acetylcholine receptor antibodies in myasthenia gravis ${ }^{22}$ and Recoverin, associated with SCLC ${ }^{23}$, have been identified as "paraneoplastic antibodies," recent reports ${ }^{24}$ suggest that only few have direct pathogenic effect on the target neuronal or neuromuscular antigen. Furthermore, the true paraneoplastic role of these antibodies is not yet clear as they can also be found in patients with non-paraneoplastic diseases. ${ }^{24}$ Therefore, while demonstration of these antibodies may help in the diagnosis of the neurological syndrome, their detection do not necessarily predict the presence of a neoplasm.

\subsection{CLASSICALANTINEURONAL ANTIBODIES}

Expert consensus has designated some autoantibodies as "well-recognized" paraneoplastic antibodies based on the weight of the scienti?c evidence; whereas others are classified as "partially recognized" because of lack of strong scienti?c support ${ }^{25}$ (table2). The 'classical' onconeural antibodies (anti-Hu, anti-Yo, Ma2, CRMP-5, amphiphysin and anti-Ri) are directed against intracellular antigens and are strongly associated with underlying malignancy. Because these antibodies are highly speci?c for the underlying neoplasm, it is difficult to exclude the diagnosis of cancer in the presence of one of these antibodies without thorough evaluation and a long period of clinical followup. ${ }^{26}$ However, these antibodies are not thought to be directly pathogenic ${ }^{27}$; for example, In 1999 Tanaka et al reported that "passive transfer of anti-Hu containing immunoglobulin $\mathrm{G}$ into animals did not induce disease. ${ }^{28}$ Similarly Benyahia et al suggested that In anti-Hu syndromes the neuropathology is likely to be cell mediated ${ }^{29}$ and the antibody is merely an immunological accompaniment. Example of classical onconeural antibodies associated with paraneoplastic disorders includes:

Anti-Hu: Is an autoantibody detected in the serum of patients with paraneoplastic subacute sensory neuronopathy and/or encephalomyelitis,

Anti-Ri: May be present in patients with opsoclonus/myoclonus syndrome

Antibodies directed against amphiphysin: Have been detected in the serum of patients with the paraneoplastic form of stiff man syndrome

Ma2: Associated with testicular cancer anti-Yo or anti-Purkinje cell antibody 1 (APCA-1): Detected in patients with paraneoplastic cerebellar degeneration

\subsection{NON-CLASSICAL ANTINEURONAL ANTIBODIES}

By contrast, onconeural antibodies directed against cell surface antigens (e.g. anti-NMDA, VGKC, AChR) have a weaker tumour association. These antibodies are believed to be directly responsible for the paraneoplastic disorders, as in the case of anti-NMDA receptor antibodies associated encephalitis, $\mathrm{P} / \mathrm{Q}$ type of voltage-gated calcium channels (VGCC) in Lambert Eaton Myasthenic syndrome (LEMS) and myasthenia gravis associated with acetylcholine receptor (AChR) antibodies. ${ }^{30}$ Several other antibodies have been proposed as possible paraneoplastic autoantibodies, but until future research establishes their aetiologic role, they will continue to be considered as "partially recognized"; these includes: anti-Tr, antiZic4, anti-mGluR1 and PCA2. ${ }^{28,31}$ Recently, new 'onconeural' antibodies (SOX antibodies) have been found in about $67 \%$ of patients with 
small cell lung cancer associated with LEMS and are reported to be highly specific to the paraneoplastic form of LEMS. ${ }^{32}$

\subsection{SUMMARY OF PATHOGENESIS}

In the final analysis, research findings thus far suggest that, antibodies are more likely to play an important pathogenic role in syndromes associated with antibodies directed against cell surface antigens. ${ }^{19}$ For example antiacetylcholine receptor antibodies in myasthenia gravis, anti-NMDA (N-methyl-Daspartic acid) receptor antibodies in limbic encephalitis, and anti-voltage-gated calcium channel (VGCC) antibodies in Lambert-Eaton syndrome. In settings where the paraneoplastic antigens are located in the cytoplasm or nucleus, a pathogenic role for the associated antineuronal antibodies has not been established. ${ }^{28}$ In these cases, indirect evidence points to cytotoxic cell mediated immunity as the most likely mechanism. ${ }^{29}$

\section{DIAGNOSIS}

Diagnosis of PNS may require a stepwise approach as follows: (i) other aetiologies for the neurological syndrome should first be considered and ruled out. (ii) aggressive search for an underlying neoplasm. (iii) using a combination of clinical features, laboratory data and patient follow-up to confirm the diagnosis of $\mathrm{PNS}^{28}{ }^{\text {'Onconeural antibody }}$ when present provides pathway to the location of the underlying neoplasm, which helps in selecting the appropriate further diagnostic tests to demonstrate the underlying neoplasm. Additionally, the type of antibody may also suggest the best treatment approach for the paraneoplastic disorder.

\subsection{CLINICALASSESSMENT}

In most patients with paraneoplastic disorder neurological syndrome may precede the tumor diagnosis with latency of diagnosis varying from few weeks to 8 years. ${ }^{25}$ Therefore, early identification of important clinical features that are associated with neoplasm can be helpful. For example, early onset of severe myasthenia gravis with progressive generalized and oropharyngeal weakness rather than ocular weakness is likely to be more associated with thymomatous myasthenia gravis than autoimmune myasthenia. ${ }^{33}$ Similarly a rapidly progressive, Lambert-Eaton Myasthenic Syndrome (LEMS) with distal involvement, autonomic dysfunction and ataxia points toward SCLC. ${ }^{34}$

\subsection{DIAGNOSTIC ROLE OF ANTINEURONAL ANTIBODIES}

Patients with paraneoplastic neurological syndrome may have detectable autoantibodies directed against nervous system structures. Demonstration of these autoantibodies is important in establishing the diagnosis of a paraneoplastic disorder and in distinguishing it from non-neoplastic conditions. In 2002, an international panel identified six (anti-Hu, ma2, anti-Yo, amphiphysin, CRMP-5, and anti- Ri) 'onconeural' antibodies as being 'well characterised'.5 Subsequently, it was recommended that "a patient with a neurological presentation whose serum is positive for a well characterised onconeural antibody should be defined as having a definite paraneoplastic syndrome, regardless of whether or not the underlying neoplasm had been found ${ }^{36}$. While patients with no 'well characterised' antibodies must have proven cancer to be diagnosed with a definite paraneoplastic neurological syndrome.

\subsection{EVALUATION FOR THE UNDERLYING NEOPLASM}

Depending on the positive antibody(s) in question, the relevant investigations in PNS includes: full blood count, liver function test, urea and electrolytes, and bone function tests. Relevant radiological examinations are CT 'chest-abdomen-pelvis'. Negative initial neuroimaging studies in PND patients with well-characterized autoantibodies should be followed by fluorodeoxyglucose-positron emission tomography ${ }^{35}$. A prospective study by Rees et al in 2001 followed later by other study by Linke et al in 2004 . $^{8,35,36}$ found whole body FDG-PET abnormality in $37-83 \%$ PNS patients with well-characterized autoantibodies in whom initial conventional imaging was negative for underlying malignancy(figure 3). Tumour markers relevant in searching for the underlying neoplasm in paraneoplastic neurological syndromes include: $\alpha$-fetoprotein and $\beta$ human chorionic gonadotrophin in suspected germ cell/ testicular tumours, CA125 in suspected ovarian tumor, prostate specific antigen in 
Table 1: Showing classification of antineuronal antibodies into classical and Nonclassical (Modified from De Angelis LM. 2009)

\section{CLASSICAL SYNDROMES}

Encephalomyelitis

Limbic encephalitis

Subacute cerebella degeneration

Opsoclonus -myoclonus

Subacute sensory neuropathy

Lambert - Eaton myasthenic syndrome

\section{NONCLASSICAL SYNDROME}

Brain stem encephalitis

Optic neuritis

Cancer associated neuropathy

Melanoma -associated

neuropathy

Stiff person syndrome

Necrotizing myelopathy

Motor neuron diseases

Acute sensory motor

neuropathy

Guillain -Barre syndrome

Brachial neuritis

Subacute/chronic sensor y

motor neuropathy

Neuropathy and

paraproteinemia

Neuropathy and vasculitis

Table 2. Well characterised onconeuronal antibodies and paraneoplastic neurological syndromes(Modified from Sadenghia and Vernino S. 2010)

\begin{tabular}{lll}
\hline Antibody & Predominant tumour & Most common PNS \\
\hline Hu (ANNA 1) & SCLC & $\begin{array}{l}\text { Encephalomyelitis, LE, PCD, } \\
\text { Sensory neuropathy, GIT. } \\
\text { Pseudoobstruction }\end{array}$ \\
CV2 (CRMP5) & SCLC, Thymoma & $\begin{array}{l}\text { Same as Hu, and ON, } \\
\text { myopathy }\end{array}$ \\
Amphiphysin & Breast, SCLC & $\begin{array}{l}\text { Stiff-Person Syndrome, } \\
\text { myelopathy, Encephalomyelitis } \\
\text { Brain stem encephalitis, }\end{array}$ \\
Ri (ANNA2) & Breast, SCLC & $\begin{array}{l}\text { Opsoclonus- Myoclonus } \\
\text { PCD }\end{array}$ \\
Yo (PCA 1) & Ovary, Breast & Limbic and Brain stem \\
Ma2 & Testicular & PCD
\end{tabular}




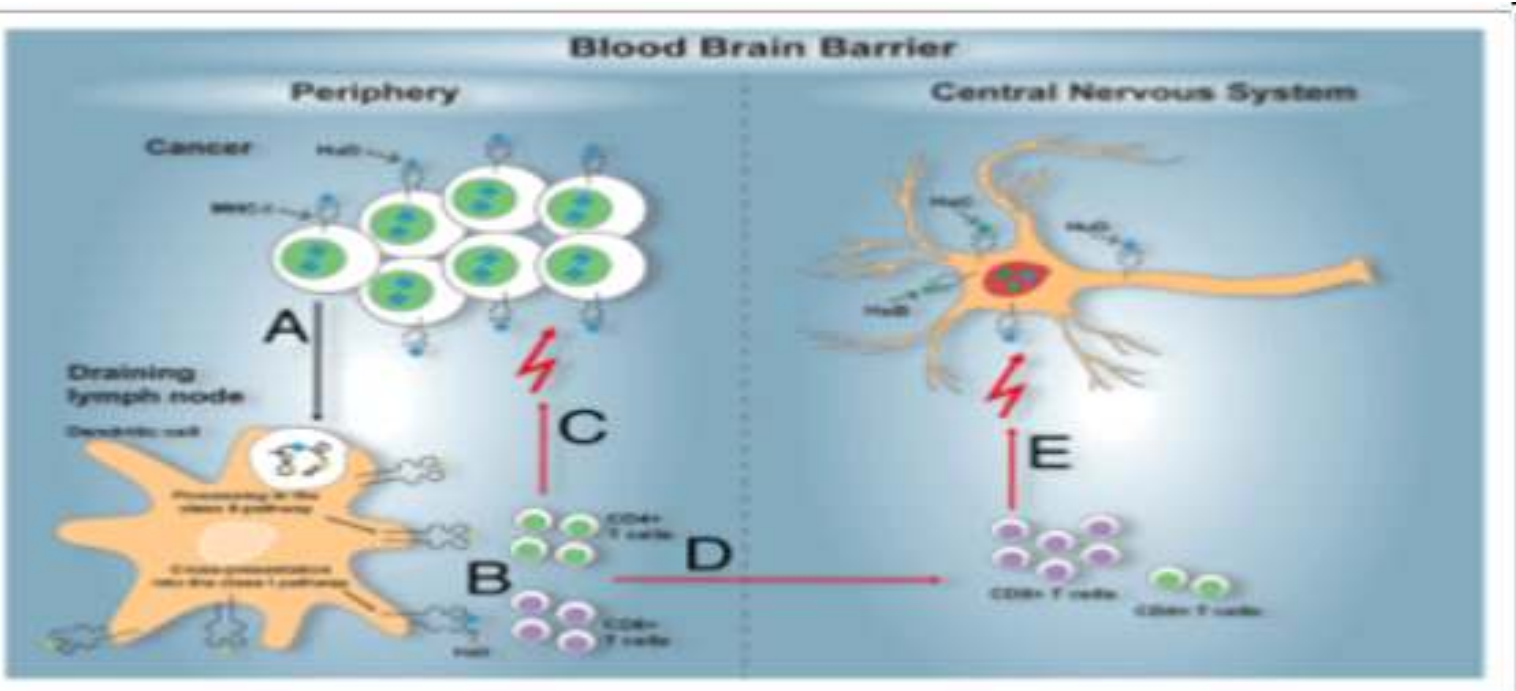

Figure 1:showing evidence of immune mediated reaction in PND (adapted from Fignolet. et al, 2013). (A). after the homing of dendritic cells to tumor-draining lymph nodes, tumor-associated antigens, are processed and presented to CD4+ and CD8 $+\mathrm{T}$ cells (B). The activated tumor-specific $\mathrm{T}$ cells reached the neoplastic lesions (C). Actvated HuD-specific $\mathrm{T}$ cells, circulate and acquire the capacity to cross the blood-brain-bamier (D). In the central nervous system (CNS) HuD-specific CDS + T cells, results in neuronal tissue damage and the related paraneoplastic neurological manifestations in the CNS(E).
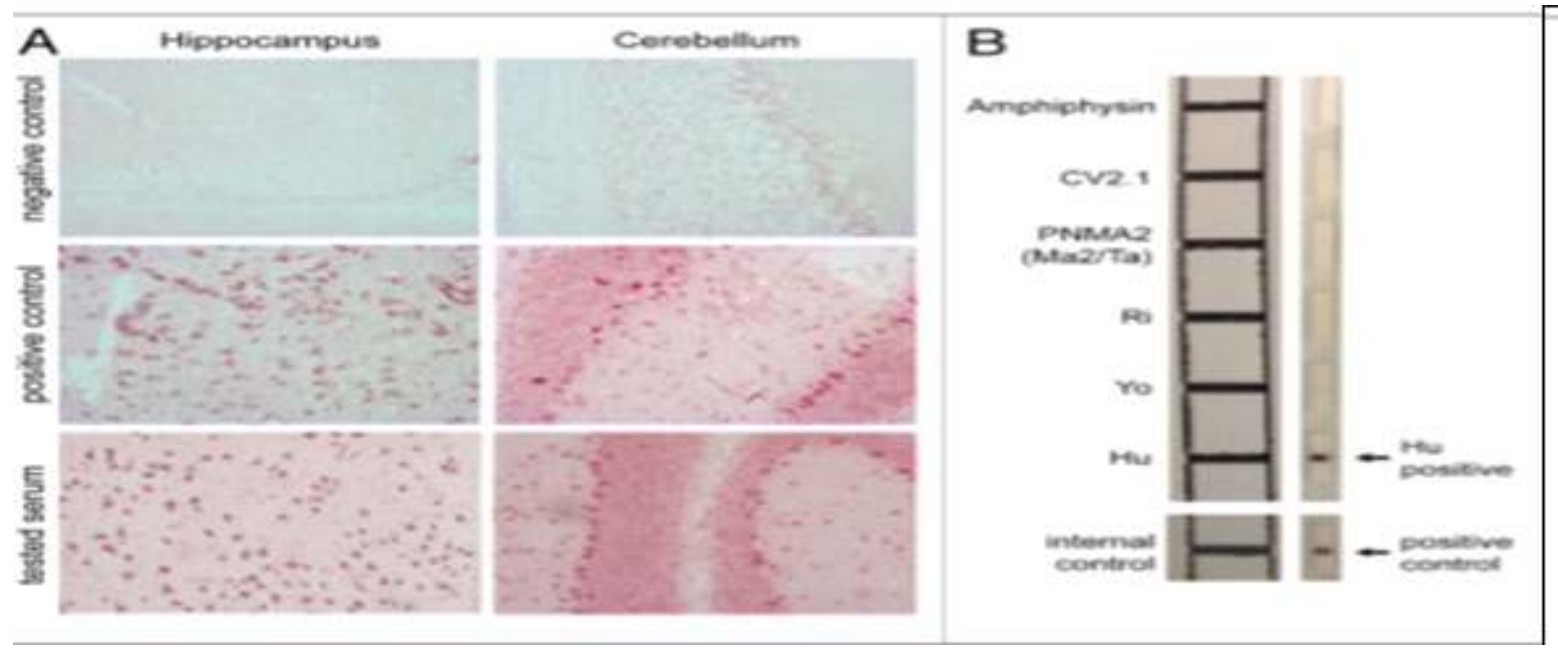

Figure 2 showing immunological reactions of some antineuronal antibodies (Modified from Pignolet et al 2013)
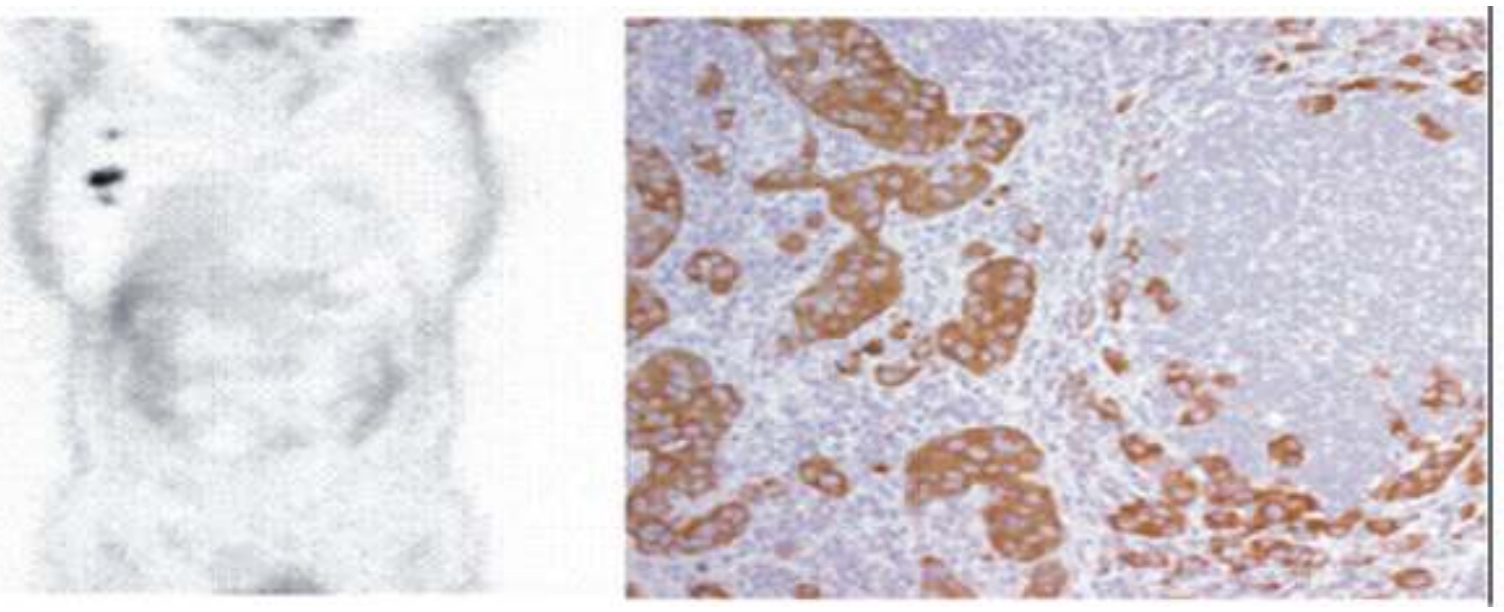

Figure 3: Showing FDG-PET scan finding of a neoplastic lesion (L) and immunological staining of anti-Yo antibody in PNS (R) (adapted from Rees JH 2001) 
suspected prostatic cancer. Other investigations are: mammography in suspected case of breast cancer, colonoscopy in suspected colorectal cancer. Suspicious lesions may warrant biopsy and sometimes appropriate initial negative investigations will require invasive tests - for example, "an anti$\mathrm{Hu}$ positive patient requires bronchoscopy even if the CT chest is normal". ${ }^{25}$

\section{TREATMENT}

\subsection{ROLE OF ANTINEURONALANTIBODIES}

Data regarding response to therapy are largely based on small retrospective studies and case reports. In a review of about 259 reported retrospective case series, only 33 cases of effective treatment were documented. ${ }^{18,37}$ "Generally, it appears that paraneoplastic disorders in which antibodies are directed against cell surface antigens are more responsive to immunotherapy". ${ }^{38}$ The PNDS that are amenable to immunotherapy includes the progressive cerebellar degeneration with antibodies directed against metabotropic glutamate receptors (mGluR1), paraneoplastic encephalitis associated with anti-NMDA receptor antibodies and neuromuscular syndromes (Lambert-Eaton syndrome, myasthenia gravis and neuromyotonia). ${ }^{21}$ In contrast, Paraneoplastic Neurological syndromes, with antibodies directed against intracellular neuronal antigens, the antibodies appears to be markers of a cell-mediated immune response against the cancer cells. These syndromes are usually characterized by selective neuronal loss and less potential for neurological recovery ${ }^{16,24,30}$ Therefore, therapy is mainly supportive that includes: physiotherapy, speech therapy, occupational therapy and symptomatic treatment with antiepileptic and analgesic medications

\subsubsection{TREATMENT OFTHE UNDERLYING NEOPLASM}

Treatment of the underlying neoplasm may stabilize the neurological syndrome and could subsequently lead to clinical improvement. ${ }^{39}$ There is evidence, ${ }^{12}$ in anti-Hu associated encephalomyelitis that early treatment of neoplasm improves neurological outcome. Other syndromes in which treatment of underlying neoplasm is known to positively affect neurological outcome are: opsoclonus-myoclonus, stiff person syndrome, myasthenia gravis, and LEMS. ${ }^{12}$

\subsubsection{IMMUNOTHERAPY}

Immunotherapy with steroids, IVIgG, plasmaphereis, cytotoxic medications and rituximab are more affective in improving neurological outcome when the syndrome is associated with an antibody directed against a cell surface antigen such as: acetylcholine receptor (AChR), voltage gated potassium channel (VGKC), N-methyl-d-aspartic acid (NMDA), and voltage gated calcium channel (VGCC). ${ }^{40}$ Recent, though uncontrolled studies and case reports suggest beneficial effect of a monoclonal antibody directed against CD20 molecule (Rituximab) in treating PNDs. ${ }^{41}$

\section{CONCLUSION}

Although paraneoplastic neurological syndromes are uncommon and not completely understood, their antibody associations are important because of the antibody's aetiological connection with the underlying neoplasm. The paraneoplastic autoantibody may provide a roadmap to early diagnosis of the underlying neoplasm, prompt treatment of which can sometimes improve the neurological outcome. The disorder often predate the diagnosis of the underlying neoplasm, providing a pathway for detecting cancer at an earlier and amenable stage. Evaluations for paraneoplastic antibodies are sometimes negative but do not rule out the diagnosis of a paraneoplastic disorder. Relevant clinical presentations should suggest a paraneoplastic syndrome, even in the absence of paraneoplastic antibodies and prompt search for occult neoplasm

\section{REFERENCES}

1 Dalmau J, Rosenfeild MR. Paraneoplastic Neurologic syndromes. In: Fauci, Braunwald, Kasper, et al. Harrison's Principles of Internal Medicine. 17th ed. Vol. 1. New York: McGraw Hill Medical. 2008; 623-7.

2. Rudnicki SA, D. J. paraneoplastic syndrome of the spinal cord, nerve and muscle. Muscle Nerve.2000; 23: 1800.

3. Graus F, Delattre JY, Antoine JC, et al. 
Recommended diagnostic criteria for paraneoplastic neurological syndromes. J Neurol Neurosurg Psychiatry,2004a; 75: 1135-40.

4. Graus F, Dalmou J, Rene R, et al. Anti-Hu antibodies in patients with small-cell lung cancer: association with complete response to therapy and improved survival. J Clin Oncol.1997; 15: 2866.

5. Pittock SJ, Kryzer TJ, L. V. Paraneoplastic antibodies coexist and predict cancer, not neurological syndrome. Ann Neurol, 2004a;56: 715-19

6. Furneaux, H.F., Reich, L. and Posner, J. B. Autoantibody synthesis in the central nervous system of patients with paraneoplastic syndromes. Neurology, 1990:40:1085-1091.

7. Keime-Guibert F, Graus F, Broët P, et al. Clinical outcome of patients with anti-Huassociated encephalomyelitis after treatment of the tumor. Neurology,1999; 53: 1719-23.

8.Rees JH, Hain SF, Johnson MR, et al.The role of [18F] fl uoro-2-deoxyglucose-PET scanning in the diagnosis of paraneoplastic neurological disorders. Brain.2001;124:2223_2231.

9. Braik T. Arthur T. Evans, Margaret Telfer, Susan McDunn, M. Paraneoplastic Neurological Syndromes: Unusual Presentations of Cancer. A Practical RevieAm J Med 2010;340(4):301-308.

10. De Angelis LM, P. J. Neurologic complications of cancer,. 2nd Edn. Oxford: Oxford University Press, 2009; 577-608.

11. Dropcho E.J. Update on paraneoplastic syndrome. Curr Opin Neurol, 2005;18: 331-336.

12. Peterson K, Rosenblum MK, Kotanides H, et al. Paraneoplastic cerebellar degeneration. I. A clinical analysis of 55 anti-Yo antibody-positive patients. Neurology, 1992; 42:1931-7.

13. Pignolet, B. S. L., Gebauer, C. M. T., Liblau, R. S., Toulouse, U. De,
Physiopathologie, C. De, \& Purpan, T. A beneficial antitumor immune response going awry Immunopathogenesis of paraneoplastic neurological syndromes associated with anti-Hu antibodies, 2013; $1-10$.

14. Bernal, F., Graus, F., Pifarre, A., Saiz, A., Benyahia, B. and Ribalta, T. Immunohistochemical analysis of anti$\mathrm{Hu}$-associated paraneoplastic encephalomyelitis. Acta Neuropathol, 2002;103:509-515.

15. Albert, M.L., Darnell, J.C., Bender, A., Francisco, L.M., Bhardwaj, N. and Darnell, R. B. Tumor-specific killer cells in paraneoplastic cerebellar degeneration. Nature Med. 1998;4:1321-1324.

16.Lachance DH, L. V. Paraneoplastic neurological autoimmunity In Neuroimmunology in Clinical Practice. In: Kalman B, Brannagan TH 3rd, Editors. Oxford: Blackwell Publishing;2008; 2107.

17. Psimaras D, Carpentier AF, R. C. PNS Euronetwork. Cerebrospinal fluid study in paraneoplastic syndromes. J Neurol Neurosurg Psychiatry, 2010;81: 42-5.

18. Dalmau J, Funeaux HM, Cordon-Cardo C, P. J. The expression of the $\mathrm{Hu}$ (paraneoplastic encephalomyellitis /sensory neuropathy) antigen in human normal and tumor tissue. Am J Pathol, 1992;141: 881 .

19. Darnell RB and DeAngelis LM. Regression of small-cell lung carcinoma in patients with paraneoplastic neuronal antibodies. Lancet 2003;341:21

20. Maddison P, Newsom-Davis J, Mills KR, S. R. Favourable prognosis in LambertEaton myasthenic syndrome and smallcell lung carcinoma. Lancet,1999; 353: 117.

21.Dalmau J, Gleichman AJ, Hughes EG, et a. Anti- NMDA-receptor encephalitis: case series and analysis of the effects of antibodies. Lancet Neurol, 2008; 7: 10918.

22. Drachman DB. Myasthenia gravis. N Engl 
J Med 1994; 330: 1797

23.Ohguro H, N. M. Pathological roles recoverin in cancer-associated retinopathy. Adv Exp Med Biol,2002; 514: 109.

24. Graus F, Saiz A, D. J. Antibodies and neuronal autoimmune disorders of the CNS. J Neurol, 2010;257: 509.

25. Graus F, Delattre JY, Antoine JC, et al. Recommended diagnostic criteria for paraneoplastic neurological syndromes. Psychiatry., J Neurosurg,2004b; 75:(8), 1135-40.

26. Voltz R. Can antibodies in serum predict the presence of microscopic tumors? Neurology, 2007;68: 887-8.

27. Smeenk RJ. Antinuclear antibodies: cause of disease or caused by disease? Rheumatology (Oxford) 2000;39:581-4

28.Tanaka K, Tanaka M, Inuzuka T, et al. Cytotoxic $\mathrm{T}$ lymphocyte-mediated cell death in paraneoplastic sensory neuronopathy with anti-Hu antibody. J Neurol Sci,1999;163:159-62.

29.Benyahia B, Liblau R, Merle-Béral H, et al. Cell- mediated autoimmunity in paraneoplastic neurological syndromes with anti-Hu antibodies. Ann Neuro, 1999;45(1), 162-7.

30.Pittock SJ. Paraneoplastic autoimmunity affecting the nervous system. In: Baehring JM, Piepmeier JM, editorsBrain Tumors Practical Guide to Diagnosis and Treatment. New York NY: Informa Healthcare, 2007;515-39.

31. Minisini AM, Pauletto G, Bergonzi P, et al. Paraneoplastic neurological syndromes and breast cancer. Regression of paraneoplastic neurological sensorimotor neuropathy in a patient with metastatic breast cancer treated with capecitabine: a case study and mini-review of the literature. Res Treat Cancer Breast, 2007;105:133-8.

32.Titulaer MJ, Klooster R, Potman M, et al. SOX antibodies in small-cell lung cancer and Lambert- Eaton myasthenic syndrome: frequency and relation with survival. J Clin Oncol, 2009;27: 4260-7.

33. Vernino S, L. V. Autoantibody profiles and neurological correlations of thymoma. Clin Cancer Res, 2004; 10:7270-5.

34.Titulaer MJ, Wirtz PW, Kuks JB, et al. The Lambert-Eaton myasthenic syndrome 1988-2008: a clinical picture in 97 patients. J Neuroimmunol, 2008; 15: 1538.

35. Linke, R., Schroeder, M., Helmberger, T. and Voltz, R. Antibody-positive paraneoplastic neurologic syndromes: value of CTand PET for tumor diagnosis. Neurology, 2004; 63: 282-286.

36. Younes-Mhenni, S., Janier, M.F., Cinotti, L., Antoine, J.C., Tronc, F., Cottin, V. et al. F.-P. improves tumour detection in patients with paraneoplastic neurological syndromes. Brain, 2004;127:,2331-2338.

37.Grisold, W., Drlicek, M., Liszka-Setinek, U. and Wondrusch, E. Anti-tumour therapy in para- neoplastic neurological disease. Clin Neurol Neurosurg, 1995;97: 106-111.

38. Bernal F, Shams'ili S, Rojas I, et al. A.-T. r antibodies as markers of paraneoplastic cerebellar degeneration and Hodgkin's disease. Neurology, 2003;60: 230-4.

39. Douglas CA, E. J. Anti-Hu antibodies may indicate a positive response to chemotherapy in paraneoplastic syndrome secondary to small-cell lung cancer. Palliat Med, 2003;17: 638-9.

40. Bell, J., Moran, C. and Blatt, J. Response to rituximab in a child with neuroblastoma and opsoclonus-myoclonus. Pediatric Blood Cancer, 2008;50: 370-371.

41. Shams'ili, S., De Beukelaar, J., Gratama, J.W., Hooijkaas, H., Van Den Bent, M., Van 'T Veer, M. et al. An uncontrolled trial of rituximab for antibody associated paraneoplastic neurological syndromes. J Neurol, 2006;253:16-20.

42. Sadeghian $\mathrm{H}$ and Vernino S. progress in the management of paraneoplastic neuronal disorders. therapeutic advances in neurological disorders, 2010;3(1): 43-52 